\title{
María Zambrano y la actitud filosófica*
}

\author{
Greta Rivara
}

L

a filósofa española María Zambrano afirma: "La filosofía es una rara ciencia que dedica la mayor parte de su esfuerzo a definirse a sí misma. 'La ciencia que buscamos', le llamó Aristóteles. Mas no fue en su tiempo cuando la filosofía se buscaba a sí misma con más ahínco. Es en los tiempos actuales cuando la filosofía agota casi totalmente su labor en buscarse a sí misma". ${ }^{1}$

Esto tal vez es así, afirma María Zambrano, porque las ciencias mismas, los saberes al delimitar sus métodos han logrado -según ellos- la cuantía clara y gloriosa de sus conocimientos; y dadas sus pretensiones de precisión, esto les ha posibilitado definir sin vacilación sus objetos. Mientras que frente a tal vanagloria, la filosofía parece haberse avergonzado de no haber conseguido tales metas culpando entonces de su desdicha, y tal vez de su "desprestigio", a la "vaguedad" de sus métodos y sus procederes.

Sin embargo, apunta Zambrano, lo curioso, y con ello lo grave, no radica en los reproches que a la filosofía se le puedan hacer desde fuera (desde discursos que mostrándose muy satisfechos por la eficacia de sus métodos y procedimientos para lograr abarcar la realidad toda y hacerla un paquete accesible, certero, claro y objetivo), sino justa y precisamente los reproches que ella, insegura e intimidada por aquellos, se hace a sí misma.

Inseguridad, sugiere Zambrano, que se hace ostensible de manera clara con Kant, quien no halla cómo hacer válida una fundamentación para la metafísica. La Crítica de la razón pura representa un intento no de Kant sino de la filosofía misma por poder justificarse a sí misma; no es gratuito el hecho de

* Comentario al ensayo inédito de María Zambrano "La actitud filosófica" (escrito alrededor de 1950). Cedido por la fundación María Zambrano para su publicación en la recopilación de textos M. Zambrano, La llama sobre el agua. Ed. de María Fernanda Santiago Bolaños. Alicante, Ediciones Aitana, 1994.

${ }^{1}$ M. Zambrano, "La actitud filosófica", en op. cit., p. 25. 
que a partir de ello, tanto Kant como kantianos -incluso no kantianos- hayan tratado de convertir a la filosofía en teoría del conocimiento, y sólo con ello recuperar su dignidad perdida o vilipendiada frente a otros órdenes del saber.

Tal intento de justificación se ha traducido, de acuerdo con María Zambrano, precisamente en restricción; tal vez lo contrario de lo que cualquier justificación no venida de la inseguridad y la indignidad podría dar por resultado.

Restricción que ha implicado a su vez renuncia, renuncia que proviene de la "idea", afirma Zambrano, y de una noción de saber que se ha impuesto: saber es saber de leyes, es decir, de relaciones universales, necesarias y de causas que se han mostrado como claras y transparentes.

La diafanidad es, entonces, la suprema cualidad, dignidad y eficacia de cualquier saber para la mentalidad moderna y racionalista, heredera fundamental de los preceptos cartesianos, según los cuales -o más bien según han sido interpretados- la diafanidad sólo se da cuando las causas aparecen claras, definidas ante la mente. "Diafanidad: claridad y distinción. La idea del saber y 'la ciencia que se busca' han estado predeterminadas por esas cualidades que resumen quizá todo lo que de la vida pretende el occidental. Por ellas ha estado dispuesta a sacrificar todo lo demás, aun la vida misma".2

¿De qué renuncia nos habla Zambrano? De una renuncia a la vida que implica la sustitución de ésta por el concepto, por el sistema, por el arreglo del devenir a regularidad y de la historia a teoría, a racionalidad, a conjunto explicable, definible, medible, cuantificable. Renuncia denunciada ya por Nietzsche al observar los caracteres de una racionalidad instrumental que se aleja de la vida en la medida en que aumenta su fe en el concepto y la explicación. Racionalidad que por ello ha podido creer que ahí -en el concepto y la explicación- está la vida, toda ella capturada, toda ella hecha clara al entendimiento de un sujeto del cual, además, proviene la certeza de esa captura y de esa explicación que se realiza sobre lo capturado. Nada ha quedado fuera de la razón en ese sistema, en ese paquete, y lo que ha quedado fuera ha sido expulsado, exiliado, por no ser enteramente diáfano, transparente y por supuesto, racional. ¿Y la vida?

La vida se le fue a esta racionalidad de las manos porque en ellas la cuadratura del sistema, con el que quería acogerla, obligó a desbordarse lo no sujeto a medida y cálculo, lo no explicable con y bajo la luz del concepto, lo no determinado por la razón de un sujeto con sus categorías; ¿y el mundo? El mundo, una cosa, una cosa representada para un sujeto representador se salió también de los puños del racionalismo.

Renuncia entonces, que además, como anota Zambrano, se hace ostensible en la misma reducción de la filosofía a teoría del conocimiento.

${ }^{2}$ Ibid., p. 26. 
Renuncia que, por otro lado, se ha dado en diversas direcciones. Por ejemplo, en el idealismo, cuya idea de la filosofía culmina en el "saber absoluto" formulado por Hegel, y que incluye tales características del saber: claro, evidente, diáfano; saber total que en su pretensión de no renunciar a nada cayó también en la renuncia de la que habla Zambrano.

En este sentido, la filósofa española considera que la diafanidad del saber absoluto hegeliano radica precisamente en su totalidad y en su transparencia porque abarca y comprende la realidad justo en su totalidad. Esto puede ser así debido a que la razón está más presente que nunca, es omniabarcante, todo lo explica, todo lo contiene, todo lo aclara, y todo se reduce a ella. Reduciéndose todo a su vez a la voluntad del sujeto, en quien tal despliegue y gloria de la razón se cumplen inexorablemente: la realidad, la vida, el ser, se han convertido en idea y sólo en eso radica su valor.

Diversas respuestas se dieron lugar a partir de la formulación del saber absoluto, o más aún, a múltiples respuestas dio lugar éste. Respuestas algunas en nombre de otras ideas aún más absolutas, o que por lo menos así lo pretendieron; y respuestas-rebeliones en nombre de la realidad o dimensiones de ella no dispuestas a reducirse sin más a "idea", como comenta Zambrano. Quedaría por verse, sin embargo, si estas últimas no terminarían también por reducirse a otra "idea".

De acuerdo con esto, parece entonces que después de Hegel, al decir de Zambrano, la filosofía extremó dos posibilidades, una de las cuales es aquella que apeló a los hechos y a la fidelidad a lo dado e inmediato; extremo visto en los positivismos y sus adyacentes. Un extremismo del que la filosofía no se libró fácilmente ya que al responder al extremismo del saber absoluto, cayó en otro, aquel de las filosofías positivas, en las que, de igual manera, la apelación a la claridad y distinción se da con la misma fuerza, sólo que ahora ésta ha de lograrse desde lo dado y el apego a él. Apego que se iba a traducir finalmente en cierta idea de verdad, de racionalidad y de conocimiento, cuyo baluarte más importante y cuyo objetivo más sagrado a seguir serían la exactitud y la precisión; deidades máximas de la ciencia.

La situación así examinada es bastante curiosa, pues llegó a parecer que la precisión, es decir, la forma extrema de la claridad y de la distinción fueron notas pertenecientes al conocimiento científico ante cuya realización la filosofía se sentía un tanto avergonzada, vacilante y en último término, heroicamente dispuesta a someterse ya que por su parte no era capaz de descubrir y proponer otro ideal del saber, otro saber no necesitado de la claridad y distinción. ${ }^{3}$

${ }^{3}$ Ibid., p. 27. 
Sumamente difícil le sería a la filosofía el hacerlo, puntualiza Zambrano, ya que claridad y distinción no representan solamente las posibilidades de las certezas y las verdades tal como lo precisó el mismo Descartes, sino que son atributos y signos que sólo se entienden y explican con relación a las "ideas" y como pertenecientes a ellas.

No menos curioso, lo sucedido con el advenimiento de los positivismos, ya que representan "el caso extraño" de una filosofía que parece importar de la ciencia aquello que la filosofía misma descubriera en su originalidad radical un día, cuando, y he aquí la ironía, no había ni podía haber habido ciencia.

Entonces, aparentemente el positivismo no había advertido que la ciencia, justo ella, no hace otra cosa que sustituir hechos por ideas, más aún, cuando aísla un hecho de los demás y se dispone a explicarlo y analizarlo con objetiva precisión ¿no ha transformado ya tal hecho en una idea?, ¿no se secciona acaso la realidad para explicarla -y tal abstracción- no supone ya una idea que unificaría tal hecho bajo una cierta categorización, elaborada, además, de manera previa?

Recordemos que justo en esto radica la crítica de la fenomenología al positivismo, el cual apeló a los hechos para luego abandonarlos.

En esta discusión menciona Zambrano a Bergson, de quien afirma que conducido justamente por su espíritu de precisión, repudió casi la totalidad de la filosofía por "intelectualista", lo que le llevó además a realizar un fino diagnóstico de la ciencia: la ciencia maneja ideas, conceptos previos y no puede encontrar una realidad diferente de la mirada con la que va a buscarla, es decir, prefigura lo que mira antes de verlo (situación que desde la fenomenología podría reprochársele).

A este respecto, Zambrano enfatiza que la mirada científica ha nacido de la mirada filosófica y sigue siendo como ella idealista. La filosofía fue quien se lanzó a transformar la realidad recibida, cercana e inmediata, en "ideas", mismas que se presentarían contrarias a la opaca e indomable pluralidad deviniente de lo real.

Pero, más aún:

[...] cuando la ciencia y más que la ciencia pura la fe en la ciencia ha hecho vacilar a la filosofía ha sucedido algo sumamente extraño, extraño porque la filosofía no reaccionó enérgica y radicalmente contra tales reproches sino que los aceptó disponiéndose a mirar dentro de esta transparencia de las ideas. Mirar dentro de la propia transparencia, mirarse a sí misma. ${ }^{4}$

${ }^{4}$ Ibid., p. 28 . 
Mas esto, según Zambrano, no era por lo visto suficiente y desde la fe positivista surgió alguien que muy lejos de contradecir a tales pretensiones más bien parecía apoyarlas en lo más sustancial. Es el mismo Bergson quien acepta plenamente el reproche del idealismo lanzado por la ciencia. No sólo lo acepta, sino que, en alguna medida, se dispone a desandar el arduo y largo trayecto recorrido a partir del "descubrimiento de las ideas". ¿Cómo?

Bergson "desciende" justamente bajo las ideas, a lo que las posibilita, y no precisamente a la conciencia exclusivamente sino a lo que engendra y ve nacer la conciencia; Bergson encuentra entonces la vida. Ahí radica su verdadera crítica, su verdadera transformación, que surgida de algo que apoyaba, se distanció fundamentalmente al encontrar lo que uno y otro extremo (idealismos de corte hegeliano y los positivismos) habían perdido radicalmente, uno explícitamente y el otro por caer en lo que había criticado.

¿Era esto una radical contradicción al interior del pensamiento y las intenciones bergsonianas? En la intuición bergsoniana lo que se afirma de manera muy puntual es justamente la distancia con respecto a las "ideas", intentando entonces realizar lo que ellas no lograron: precisión, claridad, certeza y evidencia. ¿De dónde proviene esta aparente contradicción bergsoniana?

No olvidemos también que Husserl mismo quiso mantener a la filosofía como ciencia, proporcionándole incluso aquello que le había faltado o que no lo había tenido adecuadamente; aquello que, en última instancia, sería causa de todos los reproches mencionados y a los que la filosofía creía haberse hecho merecedora: el método. Sin embargo, recordemos que tal método, que tenía por objetivo conferirle precisión y rigor al proceder filosófico, comenzaba -paradójicamente- por una crítica del concepto y de la idea; comenzaba precisamente por el simple apego a las cosas, una entrega a la realidad, supone María Zambrano.

Surgía entonces una nueva confianza, la confianza en la realidad, pero, ¿acaso no subsistía aún al menos como punto de partida un presupuesto o bien idealista o bien positivista?

Otra de las respuestas más significativas que frente a aquellos extremos surgieron, según María Zambrano, es sin lugar a dudas la de Nietzsche, quien como implacable cuestionador del idealismo y del moralismo en filosofía, cuestionó de manera radical también a todo aquello que se acercara de una u otra manera a cualquier forma de un desdichado cientificismo filosófico. Con Nietzsche, apunta Zambrano, otras significativas críticas a aquellos modos de racionalidad fueron también posibles, y no dejan aún hoy de rendir frutos.

De esta manera, según la filósofa española, en los momentos en los que la filosofía se sumerge en sí misma, se adentra con ello a su vez en la oscuridad misma de la vida. Es en estos momentos tan significativos y radicales, como el que representa Nietzsche, cuando la filosofía ha sido más fiel a sí misma; y al 
serlo ha podido también descubrirse o descubrir en sí misma rostros que había velado, aprendiendo a hurgar y mirar tras los velos de sus pretensiones, de sus vergüenzas y sus reproches, revelando entonces lo que está justamente debajo de sus creaciones: su actitud. 